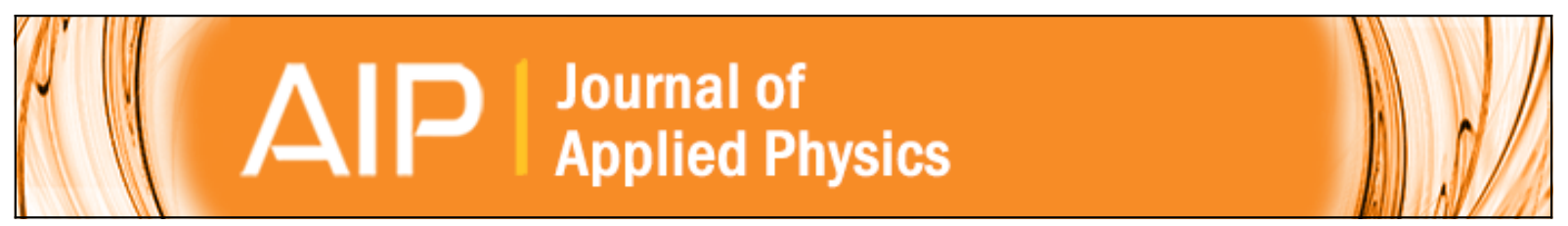

High carrier concentration induced effects on the bowing parameter and the temperature dependence of the band gap of Gaxln1xN

O. Donmez, M. Gunes, A. Erol, M. C. Arikan, and N. Balkan

Citation: Journal of Applied Physics 110, 103506 (2011); doi: 10.1063/1.3660692

View online: http://dx.doi.org/10.1063/1.3660692

View Table of Contents: http://scitation.aip.org/content/aip/journal/jap/110/10?ver=pdfcov

Published by the AIP Publishing

AlPP Re-register for Table of Content Alerts 


\title{
High carrier concentration induced effects on the bowing parameter and the temperature dependence of the band gap of $\mathrm{Ga}_{x} \mathbf{I n}_{1-x} \mathbf{N}$
}

\author{
O. Donmez, ${ }^{1}$ M. Gunes, ${ }^{1}$ A. Erol, ${ }^{1}{ }^{1, a)}$ M. C. Arikan, ${ }^{1}$ and N. Balkan ${ }^{2}$ \\ ${ }^{1}$ Science Faculty, Department of Physics, Istanbul University, Vezneciler, 34134, Istanbul, Turkey \\ ${ }^{2}$ School of Computer Science and Electronic Engineering, University of Essex, Colchester, CO4 3SQ, \\ United Kingdom
}

(Received 5 August 2011; accepted 7 October 2011; published online 17 November 2011)

\begin{abstract}
The influence of intrinsic carrier concentration on the compositional and temperature dependence of the bandgap of $\mathrm{Ga}_{\mathrm{x}} \mathrm{In}_{1-\mathrm{x}} \mathrm{N}$ is investigated in nominally undoped samples with $\mathrm{Ga}$ fractions of $x=0.019,0.062,0.324,0.52$, and 0.56 . Hall Effect results show that the free carrier density has a very weak temperature dependence and increases about a factor of 4, when the Ga composition increases from $x=0.019$ to 0.56 . The photoluminescence (PL) peak energy has also weak temperature dependence shifting to higher energies and the PL line shape becomes increasingly asymmetrical and broadens with increasing Ga composition. The observed characteristics of the PL spectra are explained in terms of the transitions from free electron to localized tail states and the high electron density induced many-body effects. The bowing parameter of $\mathrm{Ga}_{\mathrm{x}} \mathrm{In}_{1-\mathrm{x}} \mathrm{N}$ is obtained from the raw PL data as $2.5 \mathrm{eV}$. However, when the high carrier density induced effects are taken into account, it increases by about $14 \%$ to $2.9 \mathrm{eV}$. Furthermore, the temperature dependence of the PL peak becomes more pronounced and follows the expected temperature dependence of the bandgap variation. (C) 2011 American Institute of Physics. [doi:10.1063/1.3660692]
\end{abstract}

\section{INTRODUCTION}

Since the discovery of the bandgap energy of $\mathrm{InN}$ is about $0.7 \mathrm{eV}$, there has been intense research on $\mathrm{Ga}_{\mathrm{x}} \mathrm{In}_{1-\mathrm{x}} \mathrm{N}$ ternary alloys because of the possibility of fabricating optoelectronic devices based on a single material system, covering a broad spectral range of photon energies from the bandgap of $\mathrm{GaN}(x=1)$ to the bandgap of $\mathrm{InN}(x=0) .{ }^{1-4}$ Furthermore, the growth and fabrication of broad-band multitandem solar cells with increased efficiencies and radiation robustness will also be possible using $\mathrm{Ga}_{\mathrm{x}} \mathrm{In}_{1-\mathrm{x}} \mathrm{N}$ compounds. ${ }^{5}$

Temperature and compositional dependence (bowing parameter) of the bandgap are technologically important parameters of semiconductor alloys. However, a brief review of the literature shows that the reported values of these parameters in $\mathrm{Ga}_{\mathrm{x}} \mathrm{In}_{1-\mathrm{x}} \mathrm{N}$ ternary system are not consistent. Besides this common knowledge, intentionally undoped $\mathrm{Ga}_{\mathrm{x}} \mathrm{In}_{1-\mathrm{x}} \mathrm{N}$ alloy has high intrinsic electron concentration and the inconsistency in the reported values of the bandgap parameters may be related to the high intrinsic carrier concentration-induced effects. Therefore, the experimental data need to be interpreted more carefully by taking into account of the high carrier concentration effects. ${ }^{6-10}$

The aim of the current work is, therefore, to study the band parameters in $\mathrm{Ga}_{\mathrm{x}} \operatorname{In}_{1-\mathrm{x}} \mathrm{N}$ alloys with $\mathrm{Ga}$ fraction of $x=0.019,0.062,0.324,0.52,0.56$ as a function of the free carrier concentration using photoluminescence (PL) and Hall Effect measurements. The effects of the high free carrier concentration are considered using the "free-to-bound" recombination model, taking into account the conduction

${ }^{a)}$ Electronic mail: ayseerol@istanbul.edu.tr. band (CB) non-parabolicity, bandgap renormalization due to many-body effects and formation of localized states above the valence band (VB) edge.

\section{EXPERIMENTAL}

$\mathrm{Ga}_{\mathrm{x}} \mathrm{In}_{1-\mathrm{x}} \mathrm{N}$ alloys were grown by Molecular Beam Epitaxy (MBE) with a $200 \mathrm{~nm} \mathrm{GaN} \mathrm{buffer} \mathrm{layer} \mathrm{on} \mathrm{sapphire}$ substrates. The thickness of $\mathrm{Ga}_{\mathrm{x}} \mathrm{In}_{1-\mathrm{x}} \mathrm{N}$ layer were estimated from growth parameters and verified by Rutherford backscattering spectrometry as $500 \mathrm{~nm} .{ }^{11}$ Since the critical thickness of $\mathrm{Ga}_{\mathrm{x}} \operatorname{In}_{1-\mathrm{x}} \mathrm{N}$ alloys $(0<x<0.56)$ is less than $10 \mathrm{~nm},{ }^{12,13}$ we may assume that $\mathrm{Ga}_{\mathrm{x}} \mathrm{In}_{1-\mathrm{x}} \mathrm{N}$ alloys are fully relaxed. The free carrier concentrations were obtained from Hall Effect measurements. In order to determine the bandgap spectral PL measurements were carried out using the $488 \mathrm{~nm}$ line of an Ar-ion laser as the excitation source together with a $1 / 2 \mathrm{~m}$ monochromotor and a cooled GaInAs detector with a cut-off wavelength of $1.8 \mu \mathrm{m}$.

\section{RESULTS AND DISCUSSION}

The temperature dependence of free carrier concentration and carrier mobility in the samples studied are shown in Fig. 1. All the samples investigated are n-type and the electron density increases with $\mathrm{Ga}$ fraction in $\mathrm{Ga}_{\mathrm{x}} \mathrm{In}_{1-\mathrm{x}} \mathrm{N}$ alloy as shown in Fig. 1. However, free electron concentration is almost temperature independent over the temperature range between 77 and $300 \mathrm{~K}$. These observations are in good agreement with the previously reported studies. ${ }^{14,15}$ The origin of the existence of the high free electron concentration is yet to be established. But it is proposed that it may be associated with the presence of donor-like point defects due to dislocations at the interface between $\mathrm{Ga}_{\mathrm{x}} \mathrm{In}_{1-\mathrm{x}} \mathrm{N}$ and $\mathrm{GaN}$ buffer 

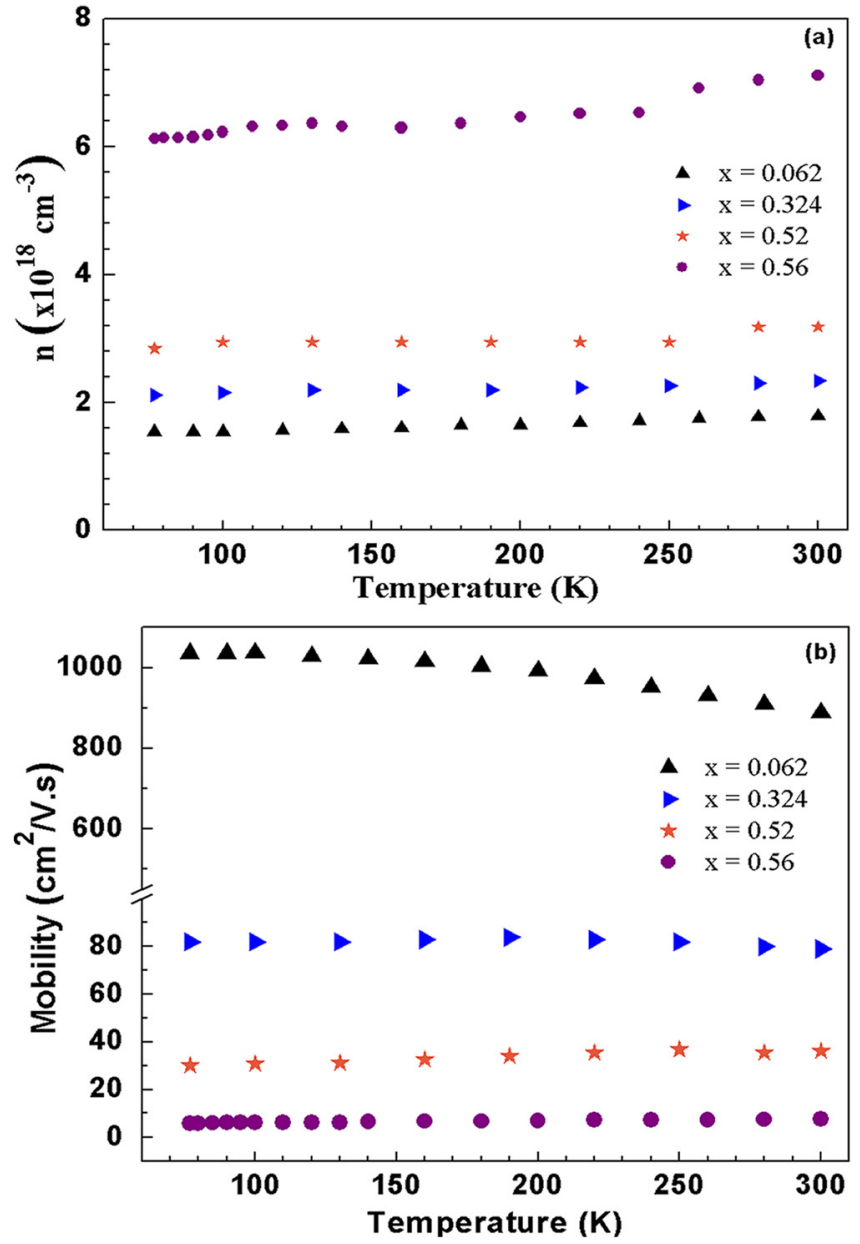

FIG. 1. (Color online) Temperature dependence of (a) free carrier concentration, and (b) mobility of the samples.

layer. ${ }^{16}$ Moreover, native defects are also considered as a source of donors. The formation of native defects is explained in terms of energy difference between Fermi level $\left(E_{F}\right)$ and Fermi stabilization energy $\left(E_{F S}\right)$ that is defined as the average energy level of native defects. When $E_{F}<E_{F S}$, native defects in the material tend to be donor and are called donor-like surface defects. ${ }^{17}$ The reduction in the mobility with increasing Ga concentration (Fig. 1(b)) may be ascribed to both the increase of the electron effective mass as the alloy becomes more GaN-like, where the effective mass is much higher $\left(0.20 \mathrm{~m}_{0}\right)$ than that in $\mathrm{InN}\left(0.04 \mathrm{~m}_{0}\right)$ and increase in the alloy scattering and scattering with donor-like defects and dislocations. ${ }^{18-20}$

The increasing of Ga composition results in a blue-shift in the PL peak energy. As shown in Fig. 2, this is accompanied with an increase in the FWHM and the appearance of an asymmetric spectral behavior. This behavior in the PL line-shape is explained with the free electron recombination band (FERB) model including the Coulomb effects of the impurity potentials for InN and GaN. ${ }^{18-20}$ In the FERB model, PL emission energy corresponds to the transition of electrons from conduction band to localized tail states in the VB. The density of states in the band tails are expressed by the rms value of the impurity potential, therefore carriers (electrons) contributing to the radiative emission are considered to be free above the $\mathrm{CB}$, while the holes are bound in

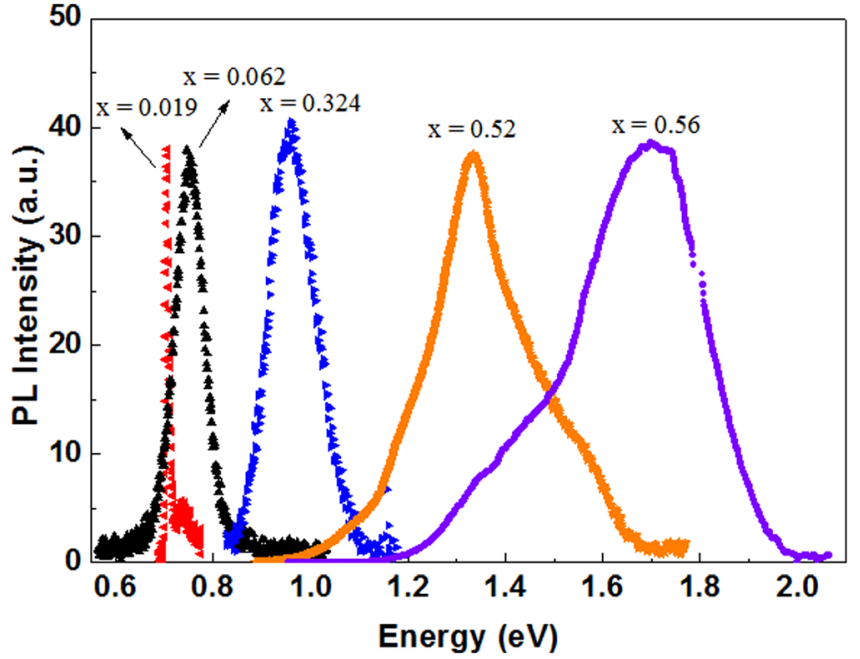

FIG. 2. (Color online) Composition dependent PL spectra of the samples at $77 \mathrm{~K}$.

the potential minima of the VB tails. Because of the high free electron concentration, the $\mathrm{CB}$ is degenerate and the Fermi level is located high in the $\mathrm{CB}$, therefore, band tailing effects on the density of states of the $\mathrm{CB}$ can be ignored.

The presence of the VB tail states as described above leads to the lowering of the PL peak energy. Also, high electron density induced many-body effects, that are electronelectron and electron-impurity interactions, are another source of bandgap narrowing. On the other hand, because of the high residual electron concentration, the alloy behaves like having the characteristic of highly doped semiconductors. Hence, the $\mathrm{CB}$ is filled by electrons and recombination mechanism is due to degenerate electrons from the $\mathrm{CB}$ density of states to the available states in the VB tails. Therefore, the PL peak energy in highly degenerate $\mathrm{Ga}_{\mathrm{x}} \mathrm{In}_{1-\mathrm{x}} \mathrm{N}$ can be explained by the interplay between the effects of nonparabolic CB and the bandgap narrowing. In Fig. 3, a schematic drawing of the optical transition from degenerate $\mathrm{CB}$ to VB tailing states is illustrated.

The PL peak energy (including high electron concentration effects) can be described as

$$
\begin{aligned}
E_{P L} & =E_{C}(k)-\left(E_{F E R B}+E_{\text {renormalization }}\right) \\
& =E_{C}(k)-\left(\Delta E_{e-e}+\Delta E_{e-i}+E_{T}^{*}\right),
\end{aligned}
$$

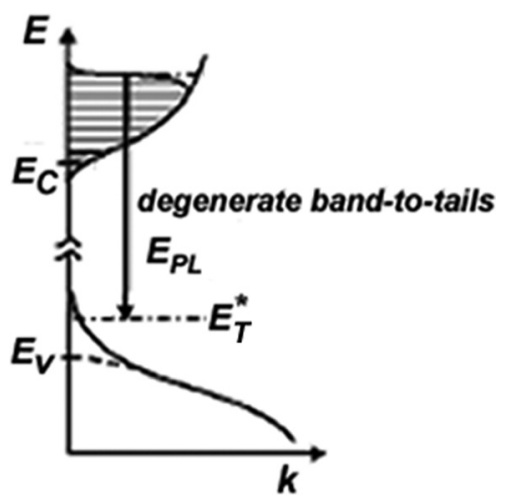

FIG. 3. A schematic drawing of the optical transition from degenerate conduction band to valance band tailing states. 
where $E_{c}(k)$ represents the non-parabolic CB dispersion relation, $\Delta E_{e-e}$ and $\Delta E_{e-i}$ are the correction terms originated from many-body effects, and $E_{T}^{*}$ is the potential minima of the VB tail near the thermal-equilibrium level.

The strong CB non-parabolicity is described by the $\boldsymbol{k} \cdot \boldsymbol{p}$ interaction across the direct band between $\mathrm{CB}$ and $\mathrm{VB}$ in semiconductors. An analytical form of the non-parabolic CB dispersion obtained by solving Kane's two band $\boldsymbol{k} \cdot \boldsymbol{p}$ model is given by ${ }^{8,21}$

$$
E_{C}(k)=E_{G}+\frac{\hbar^{2} k_{F}^{2}}{2 m_{0} e}+\frac{1}{2}\left(\sqrt{E_{G}^{2}+4 E_{P} \frac{\hbar^{2} k_{F}^{2}}{2 m_{0} e}}-E_{G}\right),
$$

where $E_{G}$ is the direct bandgap energy of the alloy, $E_{P}$ is the momentum matrix element and $k_{F}$ is the Fermi wave vector $k_{F}=\left(3 \pi^{2} n\right)^{1 / 3}$ where $n$ is the $3 \mathrm{D}$ free electron concentration. The effective mass is then $k$-dependent and given by

$$
m^{*}(k)=\frac{\hbar^{2} k}{d E_{C}(k) / d k} .
$$

$E_{T}^{*}$ can be expressed using FERB model as ${ }^{22}$

$$
E_{T}^{*}=-E_{V}+\sqrt{2} E_{T}-k_{B} T / 2 e,
$$

where $E_{V}$ is the VB edge and $E_{T}$ is the density of states in the band tails and described by the rms value of the impurity potential in the screened Coulomb potential approximation as $^{22}$

$$
E_{T}=2 \sqrt{\pi} \frac{4 \pi e}{\varepsilon R_{S}}\left(N_{i} R_{S}^{3}\right)^{1 / 2},
$$

where $\varepsilon=(10+3.2 x) \varepsilon_{0}$ is static dielectric constant of $\mathrm{Ga}_{\mathrm{x}} \mathrm{In}_{1-\mathrm{x}} \mathrm{N},{ }^{23} N_{i}=(1+K) n$ is the total ionized impurity concentration, $K$ is the compensation ratio. $K$ is taken to be zero in the calculations because there is no significant temperature dependence of free electron concentration $\left(N_{i}=n\right)$ as seen in Fig. 1(a), therefore, all impurities are ionized in the temperature range between 77 and $300 \mathrm{~K} . R_{s}$ is the Thomas-Fermi screening length in degenerate electron gas and expressed as

$$
\begin{aligned}
R_{S} & =\left(\frac{\pi}{3}\right)^{1 / 6} \frac{a_{B}}{2}\left(n a_{B}^{3}\right)^{-1 / 6}, \\
a_{B} & =\frac{\varepsilon}{16 \pi^{3} e^{2}} \frac{h^{2}}{m^{*}},
\end{aligned}
$$

where $m^{*}$ is effective electron mass and $a_{B}$ is the effective Bohr radius of electrons.

The downward-shift of the CB due to electron-electron interaction is given as ${ }^{21}$

$$
\Delta E_{e-e}=\frac{2 e k_{F}}{\pi \varepsilon}\left[1+\frac{\lambda \pi}{2 k_{F}}-\frac{\lambda}{k_{F}} \tan ^{-1}\left(\frac{k_{F}}{\lambda}\right)\right],
$$

where

$$
\lambda=\frac{2}{\sqrt{\pi}}\left(\frac{k_{F}}{a_{B}}\right)^{1 / 2}
$$

is the Thomas-Fermi screening wave vector. The contribution of electron-ionized impurity interaction to the CB downward shift can be expressed as

$$
\Delta E_{e-i}=\frac{4 \pi n e}{a_{B} \varepsilon \lambda^{3}} .
$$

If the measured PL peak energies $\left(E_{P L}\right)$ are assumed to be equal to the bandgap energy, we can obtain the bowing parameter from the composition dependence of the alloy

$$
E_{\mathrm{G}}\left(\mathrm{Ga}_{\mathrm{x}} \operatorname{In}_{1-\mathrm{x}} \mathrm{N}\right)=E_{P L}=3.42 x+0.68(1-x)-b x(1-x),
$$

where $E_{G}(\mathrm{GaN})=3.42 \mathrm{eV}$ and $E_{G}(\mathrm{InN})=0.68 \mathrm{eV}$ at $77 \mathrm{~K}^{7}$ The best fit to the experimental data for all the samples studied is obtained using a bowing parameter of $2.5 \mathrm{eV}$ (dashed line in Fig. 4). Since the bowing parameter is obtained directly from PL peak energy values, it does not reflect the real composition dependent bandgap energy of $\mathrm{Ga}_{x} \mathrm{In}_{1-\mathrm{x}} \mathrm{N}$ alloys, but contains the high carrier concentration effects. In order to find the real bowing parameter, these contributions must be eliminated from experimental PL peak energies. Therefore, all contributions to the PL peak energy given in Eqs. (4), (6), and (7) are calculated and using Eq. (1), $E_{c}(k)$ values are obtained. The best fit is then achieved using a bowing parameter of $2.9 \mathrm{eV}$ (solid line in Fig. 4). All the parameters used in the calculations together with the experimental PL peak energies are given in Table I. It is obvious that the reason of such a significant difference between obtained bowing parameters originates from high carrier concentration induced effects on the bandgap energy and explains the contradiction between the bandgap parameters obtained by different research groups. ${ }^{12,23-26}$ Our calculations showed that if the carrier concentration is higher than $10^{18} \mathrm{~cm}^{-3}$, the composition dependence of the bandgap energy of $\mathrm{Ga}_{\mathrm{x}} \mathrm{In}_{1-\mathrm{x}} \mathrm{N}$ alloy cannot be determined from PL measurements directly and high carrier concentration effects

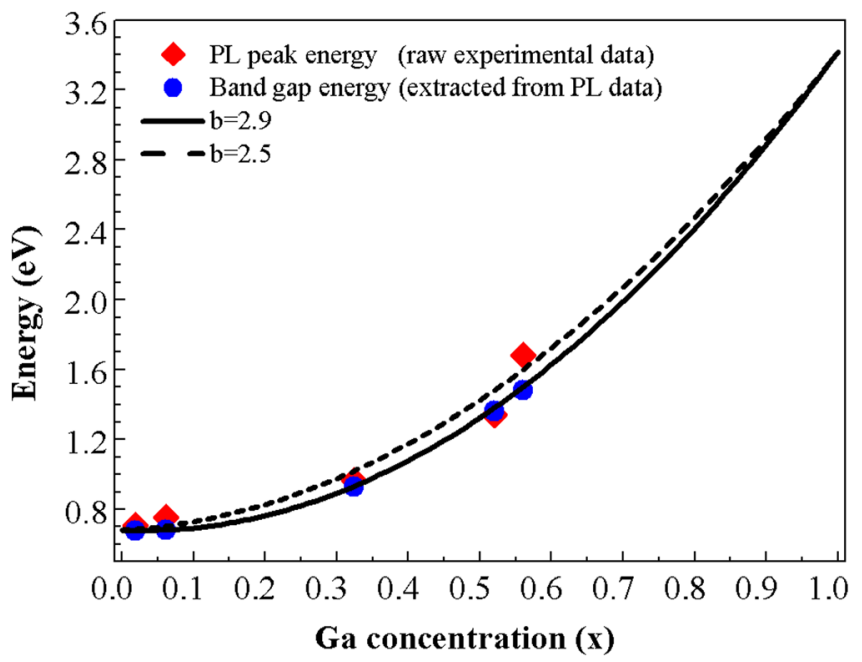

FIG. 4. (Color online) A plot of Ga composition dependence of the bandgap of $\mathrm{Ga}_{\mathrm{x}} \mathrm{In}_{1-\mathrm{x}} \mathrm{N}$ alloys using the bowing parameter as 2.9 (solid line) and 2.5 (dashed line) with the experimental peak energies of PL with (diamonds) and without (circles) high electron effects. 
TABLE I. Parameters used in the calculations, calculated values of high electron concentration induced effects and experimentally observed PL peak energy values with extracted bandgap energy of $\mathrm{Ga}_{x} \mathrm{In}_{1-\mathrm{x}} \mathrm{N}$ at $77 \mathrm{~K}$.

\begin{tabular}{lccccccccc}
\hline \hline Samples & $\begin{array}{c}\mathrm{n}\left(\times 10^{18}\right) \\
\left(\mathrm{cm}^{-3}\right)\end{array}$ & $\begin{array}{c}\mathrm{m}^{*} \\
\left(\mathrm{~m}_{0}\right)\end{array}$ & $\begin{array}{c}\mathrm{E}_{\mathrm{P}} \\
(\mathrm{eV})\end{array}$ & $\begin{array}{c}\varepsilon \\
\left(\varepsilon_{0}\right)\end{array}$ & $\begin{array}{c}E_{\mathrm{c}}(k) \\
(\mathrm{eV})\end{array}$ & $\begin{array}{c}E_{T}^{*} \\
(\mathrm{meV})\end{array}$ & $\begin{array}{c}\Delta E_{e-e} \\
(\mathrm{meV})\end{array}$ & $\begin{array}{c}\Delta E_{e-i} \\
(\mathrm{meV})\end{array}$ & $\begin{array}{c}E_{\mathrm{G}}^{\text {Calc. }} \\
(b=2.9 \mathrm{eV}) \\
(\mathrm{eV})\end{array}$ \\
\hline $\mathrm{Ga}_{0.019} \mathrm{In}_{0.981} \mathrm{~N}$ & 1.5 & 0.072 & 10 & 15.2 & 0.75 & 16 & 10 & 19 & 0.678 \\
$\mathrm{Ga}_{0.062} \mathrm{In}_{0.938} \mathrm{~N}$ & 1.54 & 0.073 & 10.2 & 14.9 & 0.76 & 16 & 10 & 19 & 0.682 \\
$\mathrm{Ga}_{0.324} \mathrm{In}_{0.676} \mathrm{~N}$ & 2.1 & 0.095 & 11 & 13.2 & 1.00 & 18 & 11 & 20 & 0.93 \\
$\mathrm{Ga}_{0.52} \mathrm{In}_{0.48} \mathrm{~N}$ & 2.8 & 0.13 & 11.7 & 12.0 & 1.42 & 19 & 13 & 21 & 0.705 \\
$\mathrm{Ga}_{0.56} \mathrm{In}_{0.44} \mathrm{~N}$ & 6.1 & 0.14 & 11.8 & 11.7 & 1.61 & 29 & 14 & 32 & 1.36 \\
\hline \hline
\end{tabular}

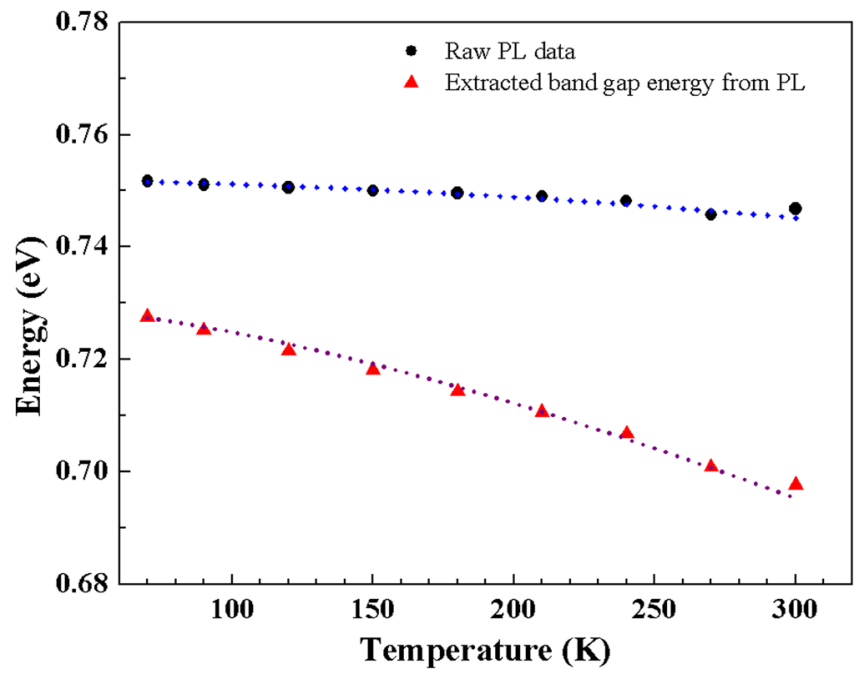

FIG. 5. (Color online) Temperature dependence of PL peak energy of $\mathrm{Ga}_{0.062} \mathrm{In}_{0.938} \mathrm{~N}$. High carrier concentration effects are included (circles) and excluded (triangles).

must be taken into account for the interpretation of $\mathrm{PL}$ spectra.

Temperature dependent PL measurements were also carried out on the samples in order to determine the true temperature dependence of bandgap energy. Figure 5 shows the temperature dependence of the measured PL energy for $\mathrm{Ga}_{0.062} \mathrm{In}_{0.938} \mathrm{~N}$. There is a weak temperature dependence (only $5 \mathrm{meV}$ reduction when the temperature range is increased from 77 to $300 \mathrm{~K}$ ). However, when the high electron concentration effects are taken into account as described above, it is seen that the PL peak energy has stronger temperature dependence and the shift is $30 \mathrm{meV}$ and closer to that as expected from the bandgap shrinkage with temperature. ${ }^{27}$ Similar results are obtained for all our samples for studied range of $\mathrm{Ga}$ compositions.

\section{CONCLUSIONS}

The influence of the high carrier concentration on the temperature and compositional dependence (bowing parameter) of the bandgap in $\mathrm{Ga}_{\mathrm{x}} \mathrm{In}_{1-\mathrm{x}} \mathrm{N}$ alloys are investigated using the free-to-bound recombination model together with the band renormalization effects in a non-parabolic $\boldsymbol{k} \cdot \boldsymbol{p}$ model. The results are then used to interpret the experimental results. It is shown that for free electron densities higher than $1.0 \times 10^{18} \mathrm{~cm}^{-3}$, PL data underestimates the temperature and compositional dependence of the bandgap energy, and this may be the cause of conflicting data in the literature. Our calculations exhibited that if the carrier concentration is higher than $10^{18} \mathrm{~cm}^{-3}$, compositional and temperature dependence of the bandgap energy of $\mathrm{Ga}_{\mathrm{x}} \mathrm{In}_{1-\mathrm{x}} \mathrm{N}$ alloy cannot be determined from PL measurements directly and high carrier concentration effects must be taken into account for the interpretation of PL spectrum.

\section{ACKNOWLEDGMENTS}

This work was supported by Scientific Projects Coordination Unit of Istanbul University with Project Nos. 9571 and UDP 16547. We acknowledge partial support from Turkish State Planning Organization (Project No. 2010K121050). We would like to thank COST action MP0805.

${ }^{1}$ K. S. A. Butcher and T. L. Tansley, Superlattices Microstruct. 38, 1 (2005).

${ }^{2}$ W. Walukiewicz, J. W. Ager III, K. M. Yu, Z. Liliental-Weber, J. Wu, S. X. Li, R. E. Jones, and J. D. Denlinger, J. Phys. D: Appl. Phys. 39, R83 (2006).

${ }^{3}$ M. D. McCluskey, C. G. Van de Walle, L. T. Romano, B. S. Krusor, and N. M. Johnson, J. Appl. Phys. 93, 4340 (2003)

${ }^{4}$ P. G. Moses and C. G. Van de Walle, Appl. Phys. Lett. 96, 021908 (2010).

${ }^{5}$ J. Wu, W. Walukiewicz, K. M. Yu, W. Shan, J. W. Ager III, E. E. Haller, H. Lu, W. J. Schaff, W. K. Metzger, and S. Kurtz, J. Appl. Phys. 94, 6477 (2003)

${ }^{6}$ J. Wu, W. Walukiewicz, S. X. Li, R. Armitage, J. C. Ho, E. R. Weber, E. E. Haller, H. Lu, W. J. Schaff, A. Barcz, and R. Jakiela, Appl. Phys. Lett. 84, 2805 (2004)

${ }^{7}$ O. Donmez, M. Yilmaz, A. Erol, B. Ulug, M. C. Arikan, A. Ulug, A. O. Ajagunna, E. Iliopoulos, and A. Georgakilas, Phys. Status Solidi B 248, 1172 (2011).

${ }^{8}$ B. Arnaudov, T. Paskova, P. P. Paskov, B. Magnusson, E. Valcheva, B. Monemar, H. Lu, W. J. Schaff, H. Amano, and I. Akasaki, Phys. Rev. B 69, 115216 (2004).

${ }^{9}$ B. Monemar, P. P. Paskov, and A. Kasic, Superlattices Microstruct. 38, 38-56 (2005).

${ }^{10}$ J. Wu, W. Walukiewicz, W. Shan, K. M. Yu, J. W. Ager III, E. E. Haller, H. Lu, and W. J. Schaff, Phys. Rev. B 66, 201403 (2002)

${ }^{11}$ E. Tiras, M. Gunes, N. Balkan, and W. J. Schaff, Phys. Status Solidi B 247, 189 (2010).

${ }^{12}$ Y. Ishitani, M. Fujiwara, T. Shinada, X. Wang, S.-B. Che, and A. Yoshikawa, Phys. Status Solidi C 4, 2428 (2007).

${ }^{13}$ P. Schley, R. Goldhahn, A. T. Winzer, G. Gobsch, V. Cimalla, O. Ambacher, M. Rakel, C. Cobet, N. Esser, H. Lu, and W. J. Schaff, Phys. Status Solidi B 243, 1572 (2006).

${ }^{14}$ M. Gunes, N. Balkan, D. Zanato, and W. J. Schaff, Microelectron. J. 40, 872 (2009).

${ }^{15}$ M. Gunes, N. Balkan, M. Yilmaz, B. Ulug, A. Ulug, and W. J. Schaff, AIP Conf. Proc. 1288, 178 (2010).

${ }^{16}$ S. X. Li, E. E. Haller, K. M. Yu, W. Walukiewicz, J. W. Ager III, J. Wu, W. Shan, H. Lu, and W. J. Schaff, Appl. Phys. Lett. 87, 161905 (2005)

${ }^{17}$ W. Walukiewicz, Appl. Phys. Lett. 54, 2094 (1989) 
${ }^{18}$ V. Lebedev, V. M. Polyakov, S. Hauguth-Frank, V. Cimalla, C. Y. Wang, G. Ecke, F. Schwierz, A. Schober, J. G. Lozano, F. M. Morales, D. González, and O. Ambacher, J. Appl. Phys. 103, 073715 (2008).

${ }^{19}$ Z. Liliental-Weber, D. N. Zakharov, K. M. Yu, J. W. Ager III, W. Walukiewicz, E. E. Haller, H. Lu, and William J. Schaff, J. Electron Microsc. 54, 243 (2005).

${ }^{20}$ J. W. Ager, W. Walukiewicz, W. Shan, K. M. Yu, S. X. Li, E. E. Haller, H. Lu, and W. J. Schaff, Phys. Rev. B 72, 155204 (2005).

${ }^{21}$ S. P. Fu, T. T. Chen, and Y. F. Chen, Semicond. Sci. Technol. 21, 244 (2006).

${ }^{22}$ B. Arnaudov, T. Paskova, E. M. Goldys, S. Evtimova, and B. Monemar, Phys. Rev. B 64, 045213 (2001).
${ }^{23}$ R. Kudrawiec, M. Siekacz, M. Krysko, G. Cywinski, J. Misiewicz, and C. Skierbiszewski, J. Appl. Phys. 106, 113517 (2009).

${ }^{24}$ R. R. Pelá, C. Caetano, M. Marques, L. G. Ferreira, J. Furthmüller, and L. K. Teles, Appl. Phys. Lett. 98, 151907 (2011)

${ }^{25}$ B. O. Liou, S. H. Yen, and Y. K. Kuo, Proc. SPIE 5628, 296 (2005).

${ }^{26}$ V. Y. Davydov, A. A. Klochikhin, V. V. Emtsev, A. V. Sakharov, S. V. Ivanov, V. A. Vekshin, F. Bechstedt, J. Furthmueller, J. Aderhold, J. Graul, A. V. Mudryi, H. Harima, A. Hashimoto, A. Yamamoto, J. Wu, E. E. Haller, and H. Feick, Proc. SPIE 5023, 68 (2002).

${ }^{27}$ J. Wu, W. Walukiewicz, W. Shan, K. M. Yu, J. W. Ager III, S. X. Li, E. E. Haller, H. Lu, and W. J. Schaff, J. Appl. Phys. 94, 4457 (2003). 